\title{
Reconstrução digital de volume de eletrodo de PaCOS para cálculo de porosidade e tortuosidade
}

\section{Volume reconstruction of SOFC electrode for \\ porosity and tortuosity calculation}

\author{
${ }^{1}$ SIM Consultoria. Av. Hélio de Almeida, S/N. Bl. 2. Sala 24 \\ Cidade Universitária. Rio de Janeiro, RJ. CEP: 21941-614 \\ e-mail: bernardo.sarruf@simateriais.com , rafaelcidade@metalmat.ufrj.br, \\ vitor.py@simateriais.com \\ ${ }^{2}$ Laboratório de Hidrogênio - LabH2 - PEMM/COPPE/UFRJ CP: 68505 \\ Cidade Universitária. Rio de Janeiro, RJ. CEP 21942-971 \\ e-mail:pmiranda@labh2.coppe.ufrj.br \\ ${ }^{3}$ Laboratório de Compósitos - LaCOM - PEMM/COPPE/UFRJ \\ Cidade Universitária. Rio de Janeiro, RJ. CEP 21942-971
}

\section{RESUMO}

O objetivo do presente trabalho é aplicar técnicas de medição de porosidade e tortuosidade através da reconstrução digital de volume. A técnica pode ser aplicada em eletrodos reais de PaCOS onde a amostra é seccionada através de feixe de íons focalizado (FIF). A reconstrução é feita a partir das imagens de cada camada da amostra gerada pelo FIF.

Os parâmetros geométricos, porosidade e tortuosidade, foram calculados a partir do empilhamento das imagens binarizadas. A porosidade foi obtida pela razão entre os voxels referentes aos poros e o volume total da amostra. A tortuosidade foi estimada com base no algoritmo Andarilhos Aleatórios, que simula as condições de difusão molecular, sem inserir um viés de direção preferencial.

O uso da reconstrução 3D propiciou resultados de cálculo de porosidade mais precisos do que a classificação tradicional em duas dimensões. O modelo difusional descrito pelo algoritmo Andarilhos Aleatórios resultou em valores coerentes e aceitáveis do cálculo da tortuosidade.

Palavras-chave: Feixe de íons focalizado, Processamento de Imagens, Pilhas a combustível de óxidos sólidos, porosidade, tortuosidade.

\section{ABSTRACT}

The aim of this work is to make tortuosity and porosity measurements by the use of digital volume reconstruction technique. It can be applied on real SOFC electrodes where the sample is sliced by focused ion beam (FIB). The reconstruction is done from the images of each layer of the sample generated by FIB.

The geometric parameters, such as porosity and tortuosity, were calculated from a stack of binary images. Porosity was obtained by the ratio between the voxels concerned to pores and the total sample volume. Tortuosity was measured by the use of the Random Walkers algorithm that simulates molecular diffusion conditions without adding a preferential direction bias.

The use of 3D reconstruction provided results of porosity calculation more accurate than the traditional classification in two dimensions. The diffusional model described by Random Walkers algorithm represented coherent and well acceptable values for tortuosity.

Keywords: Focused ion beam, Image Processing, Solid oxide fuel cells, porosity, tortuosity. 


\section{INTRODUÇÃO}

Pilhas a combustível de óxido sólido (PaCOS) têm demonstrado ser uma tecnologia bastante promissora na produção de energia elétrica. Estes dispositivos, se apresentam como os mais eficientes já inventados para conversão de energia química em elétrica. As PaCOS podem se apresentar em configuração planar ou tubular, porém pilhas planares demonstram atualmente serem o estado da arte [1, 2, $\underline{3}$.

O desenvolvimento de materiais adequados que compõem tais dispositivos depende da caracterização de variáveis microestruturais complexas, como a quantificação de poros presentes no material desenvolvido, a densidade de sítios reativos (regiões de tripla fase, RTF), tortuosidade dos poros, entre outras.

A reconstrução digital de volume, através de técnicas avançadas de microscopia eletrônica de varredura e feixe de íons focalizado (FIF), apresenta-se como alternativa de estudo mais aprofundado da microsestrutura desses materiais, permitindo o domínio da geometria de uma parte da amostra.

O objetivo do presente trabalho é promover, com a auxílio de técnicas de processamento de imagens, a reconstrução de parte do volume de um anodo de Níquel e Céria dopada com Gadolíneo (Ni/CGO) de PaCOS, para posterior cálculo da porosidade e tortuosidade do caminho traçado pelos poros.

\section{MATERIAIS E MÉTODOS}

O presente trabalho se propõe à aplicação de algoritmos de processamento de imagens e simulação, utilizando para tal, imagem obtida por feixe de íons focalizado (FIF), mostrada na Figura 1. A imagem em questão é referente a um anodo de Níquel e Céria dopada com Gadolíneo. A produção da amostra e a técnica de FIF foram aplicadas por pesquisadores da École Polytechnique Fédéral de Lausanne, Suíça [4].

O duplo feixe é uma técnica que possibilita a análise tridimensional através de camadas ao longo de uma componente de altura. O empilhamento das camadas é demonstrado na Figura 1.

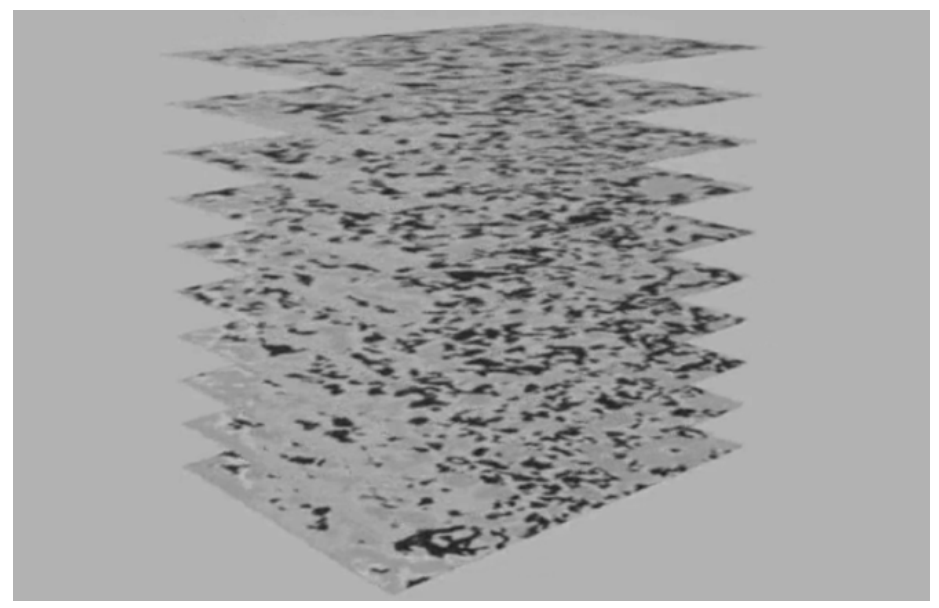

Figura 1: Representação do empilhamento das imagens. Adaptado de [4].

\subsection{Reconstrução do volume}

A imagem do anodo é constituída por 300 camadas obtidas ao longo de toda a altura da amostra, com passos de $50 \mathrm{~nm}$ entre cada camada. Para diminuição dos ruídos foi aplicado o filtro da mediana. Por fim, as imagens resultantes foram segmentadas a partir de um limiar aplicado ao nível de cinza que possibilitou a identificação da estrutura dos poros e sua reconstrução tridimensional. O volume reconstruído é representado por um paralelepípedo com dimensões 20,4x17,7x15,0 $\mu \mathrm{m}$ (cotas expressas na Figura 2), onde cada voxel representa um cubo normalizado com aresta de $50 \mathrm{~nm}$ [4].

Na Figura 3 é mostrada a sequência de pré-processamento das imagens antes da reconstrução de volume. 


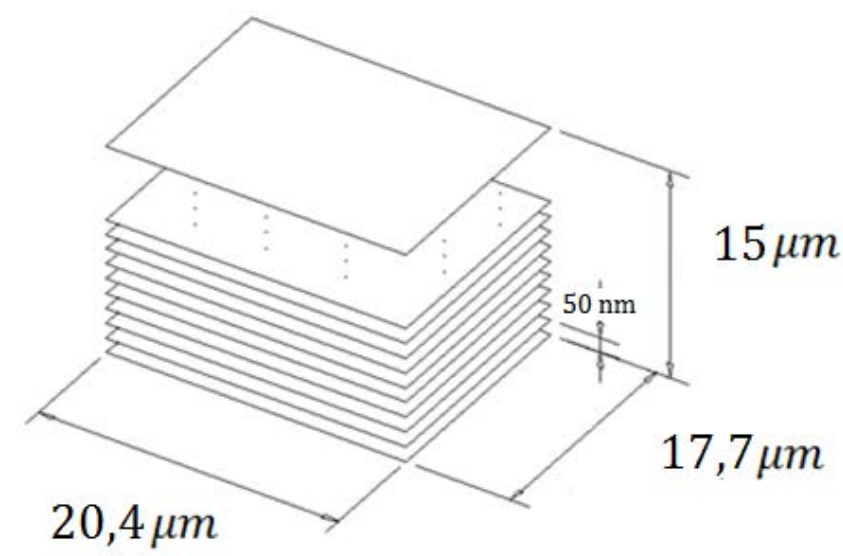

Figura 2: Representação das medidas das camadas e o passo no FIF.

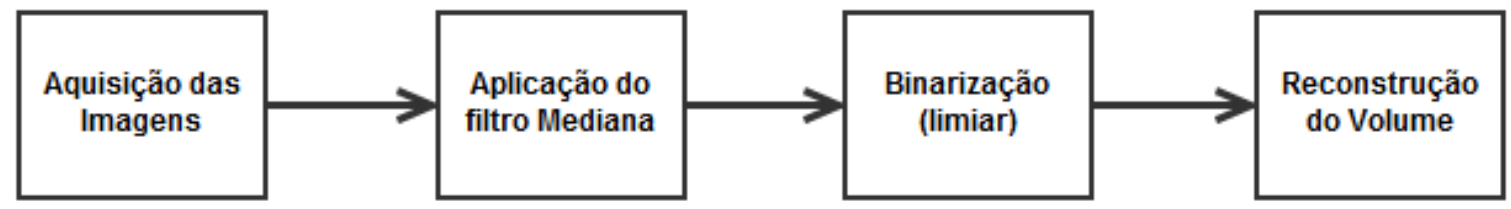

Figura 3: Pré-processamento da imagem.

\subsection{Obtenção dos parâmetros geométricos}

\subsubsection{Porosidade}

As imagens a princípio apresentam uma distribuição em nível de cinza, onde sua intensidade vai de 0 (preto) a 255 (branco). Na binarização, através de uma análise de histograma, um valor limiar corta a distribuição e cada pixel é definido como 0 ou 1, tornando possível classificar cada imagem em duas partes distintas (sólido e poros).

A partir dessas informações, a porosidade $(\varphi)$ do material foi calculada tomando a relação entre o número de voxels classificados como poros $\left(n_{\text {poro }}\right)$ e o número total de voxels do volume reconstruído $\left(n_{\text {total }}\right)$, segundo a Equação 1.

$$
\phi=\frac{n_{\text {poro }}}{n_{\text {total }}} .100 \%
$$

\subsubsection{Tortuosidade}

A tortuosidade em um meio poroso é expressa geometricamente por uma razão entre a distância curva que o gás percorre nos poros sinuosos e a distância reta entre o ponto de início e fim do caminho. Na Figura 4, mostra-se uma representação geral da tortuosidade $(\tau)$, onde "l” é o comprimento da linha azul (tortuosa) e “ $r$ ” o comprimento da linha preta (reta).

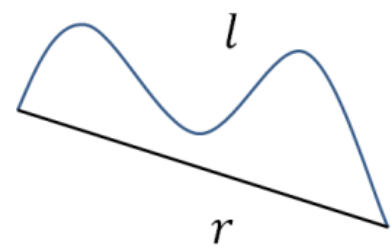

$$
\tau=\frac{l}{r}
$$

Figura 4: Representação simplificada da tortuosidade. 
A tortuosidade dos poros foi calculada com base no algoritmo Andarilhos Aleatórios [5]. Neste algoritmo são distribuídas entidades de monitoramento, chamadas andarilhos, aleatoriamente pelos "voxels" da estrutura em que se deseja estimar a tortuosidade (neste caso, os poros), e estes "voxels" representam seus pontos de partida. A ideia dos andarilhos é simular o movimento browniano de difusão molecular pelos poros, tomando-se certa aleatoriedade e considerando a colisão das moléculas nas paredes sólidas.

Cada andarilho escolhe aleatoriamente um dos vizinhos de sua posição atual, sendo aquele vizinho um poro (voxel preto) o andarilho assume sua posição e é calculada a distância entre o ponto atual e o inicial, caso contrário, o andarilho retorna à posição da iteração anterior e mesmo assim é calculada a distância entre o ponto atual e o inicial (nesse caso não houve variação da distância). Este procedimento (Figura 5) é repetido para " $t$ ” iterações, onde em cada uma é calculada a distância quadrática do andarilho para o ponto inicial. O algoritmo, de fato mede a taxa de variação em relação ao número de iterações, onde quando o andarilho assumir posições reconhecidas como espaços vazios, significará que ele variou sua posição e caso contrário significará que ele foi impedido por uma barreira sólida. As Equações 2, 3, 4 e 5 mostram o cálculo das distâncias quadráticas nas três direções do espaço e sua resultante. Observa-se que cada iteração apresenta-se como incrementos discretos de tempo.

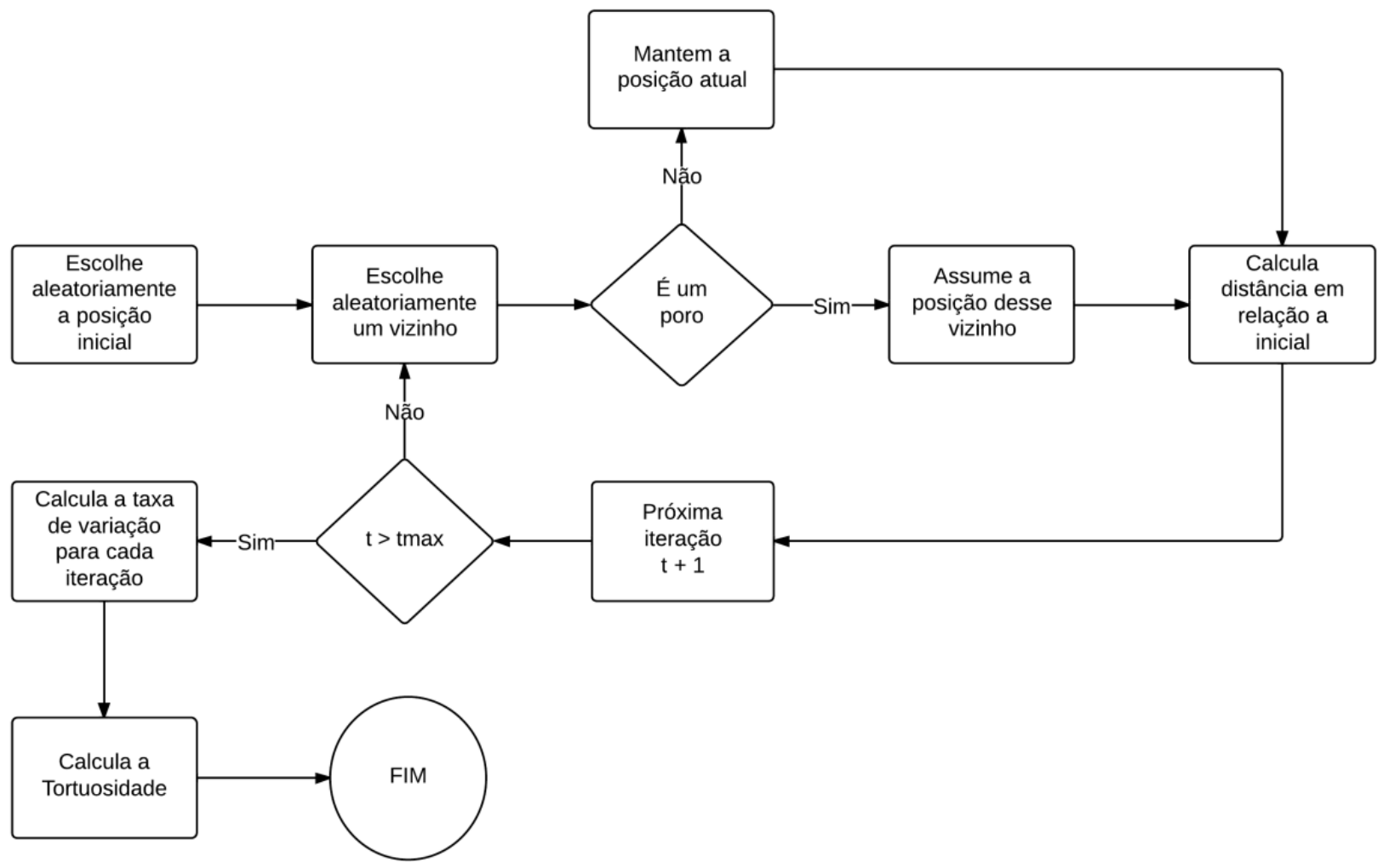

Figura 5: Representação do Algoritmo Andarilhos Aleatórios.

$$
\left\langle r^{2}(t)\right\rangle=\left\langle x^{2}(t)\right\rangle+\left\langle y^{2}(t)\right\rangle+\left\langle z^{2}(t)\right\rangle
$$

Onde

$$
\begin{aligned}
\left\langle x^{2}(t)\right\rangle & =\frac{1}{n} \sum_{i=1}^{n}\left\{x_{i}(t)-x_{i}(0)\right\}^{2} \\
\left\langle y^{2}(t)\right\rangle & =\frac{1}{n} \sum_{i=1}^{n}\left\{y_{i}(t)-y_{i}(0)\right\}^{2} \\
\left\langle z^{2}(t)\right\rangle & =\frac{1}{n} \sum_{i=1}^{n}\left\{z_{i}(t)-z_{i}(0)\right\}^{2}
\end{aligned}
$$


Onde $x, y e z$ são as coordenadas de deslocamento para cada uma das direções no espaço e " $t$ " representa as iterações. O procedimento de Andarilhos Aleatórios é realizado duas vezes. A primeira vez na imagem do anodo onde há impedimentos para seu deslocamento (caminho tortuoso) equivalente a linha "l" da Figura 4. Na segunda vez o procedimento é realizado com o mesmo número de iterações em uma imagem onde não há impedimento para difusão, ou seja, um vazio. Esse procedimento representa a linha " $r$ " da Figura 4. Como ao final, esses procedimentos são comparados e é calculada uma razão, não importam as unidades expressas.

Após realizado o cálculo das distâncias quadráticas médias, para as três direções, a tortuosidade é calculada a partir do conceito de difusividade efetiva, mostrado nas Equações 6, 7 e 8 [5, $\underline{6]}$.

$$
\begin{aligned}
& D=\frac{1}{6} \frac{d}{d t}\left\langle r^{2}(t)\right\rangle \\
& D^{e f}=V_{\text {poros }} \frac{1}{6} \frac{d}{d t}\left\langle r^{2}(t)\right\rangle_{\text {poros }} \\
& \tau_{\text {poros }}=\frac{D}{D^{e f} / V_{\text {poros }}}=\frac{d}{d t}\left\langle r^{2}(t)\right\rangle / \frac{d}{d t}\left\langle r^{2}(t)\right\rangle_{\text {poros }}
\end{aligned}
$$

onde $D$ é o coeficiente de difusão, $D^{e f}$ o coeficiente de difusão efetiva, $V_{\text {poros }}$ é o volume de poros e $\tau_{\text {poros }}$ a tortuosidade do meio poroso. Na Equação 8 é expressa a razão entre o movimento realizado sem impedimentos e o caso do movimento limitado pela parede dos poros (representado pelo subscrito "poros"). Analogamente pode-se calcular a tortuosidade em cada uma das direções $x, y, z$ utlizando as distâncias decompostas nestes três eixos, ao invés de sua resultante. Observa-se fisicamente que por análise dimensional $d r / d t$, representa uma velocidade $\left(L . s^{-1}\right.$ - variações de espaço por tempo), que no caso computacional são expressos em pixels.iteração ${ }^{-1}$.

Foi realizado também um estudo de sensibilidade do valor de tortuosidade em relação ao número de iterações realizadas no algoritmo Andarilhos Aleatórios. O valor foi calculado em intervalos de 1.000 .000 de iterações entre 0 e 10.000 .000 no intuito de avaliar o número mínimo de iterações necessárias para ocorrer a convergêcia no comportamento das curvas.

\section{RESULTADOS}

Realizado o processo de binarização, o volume foi reconstruído, a título ilustrativo, como mostra a Figura 5. A Equação 1 fornece o resultado de porosidade total em torno de 32,43\%.

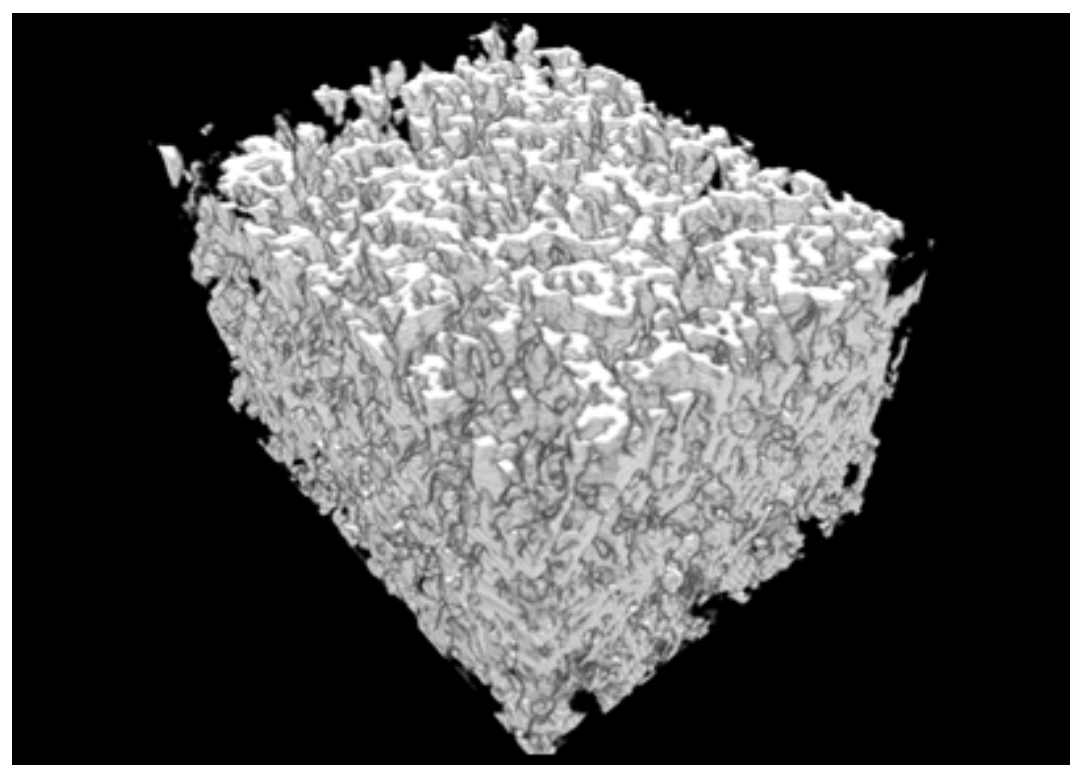

Figura 6: Representação do volume reconstruído. 
A componente de tortuosidade $\tau_{x}$ apresentou um valor acima do esperado para 10.000.000 de iterações, não apresentando convergência significativa como nas duas outras componentes $\left(\tau_{y}\right.$ e $\left.\tau_{z}\right)$, como pode ser visto na Figura 7.

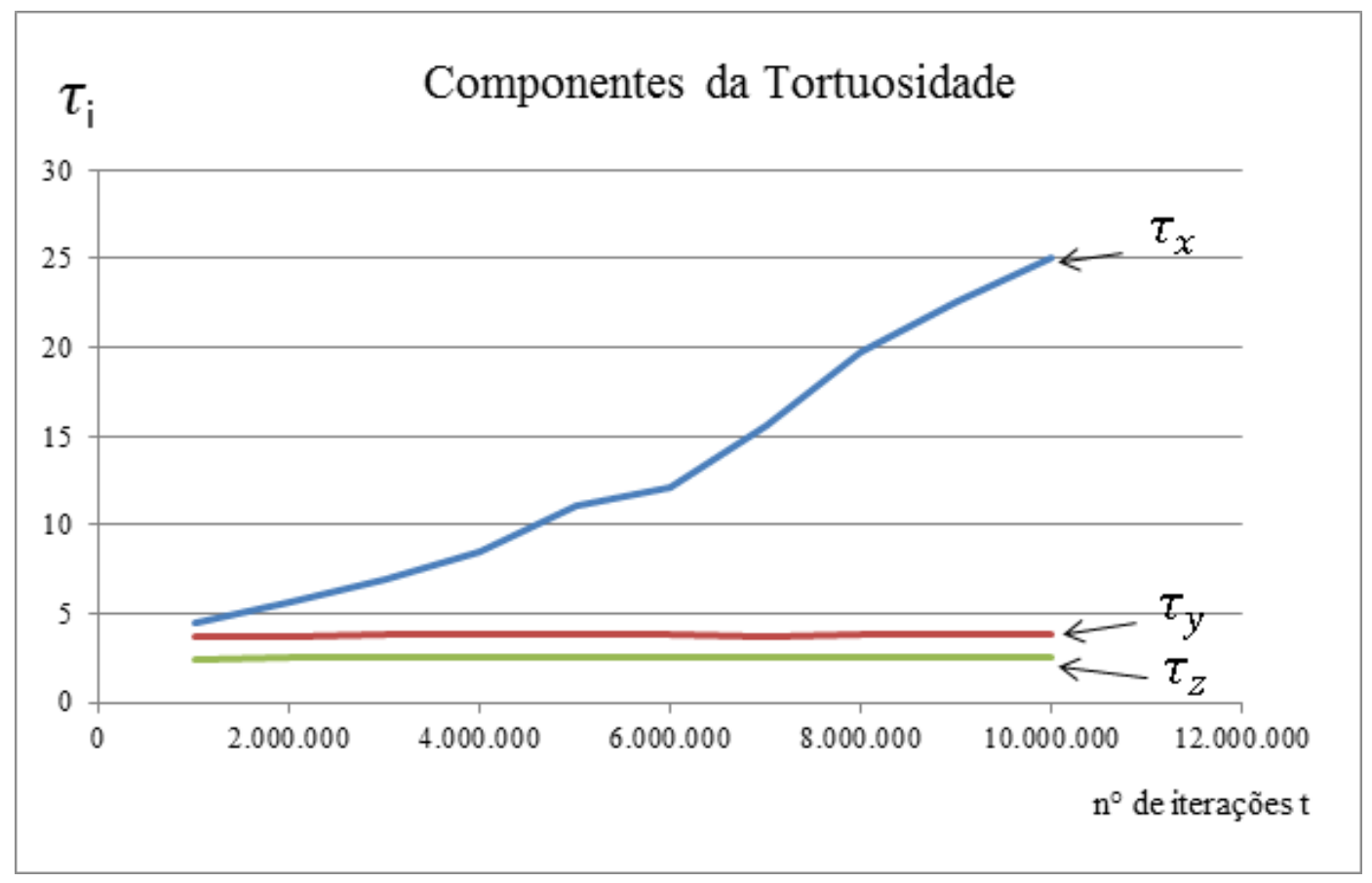

Figura 7: Gráfico da tortuosidade nas três direções.

Como resultante dessas curvas tem-se a tortuosidade, como demonstra a Figura 8.

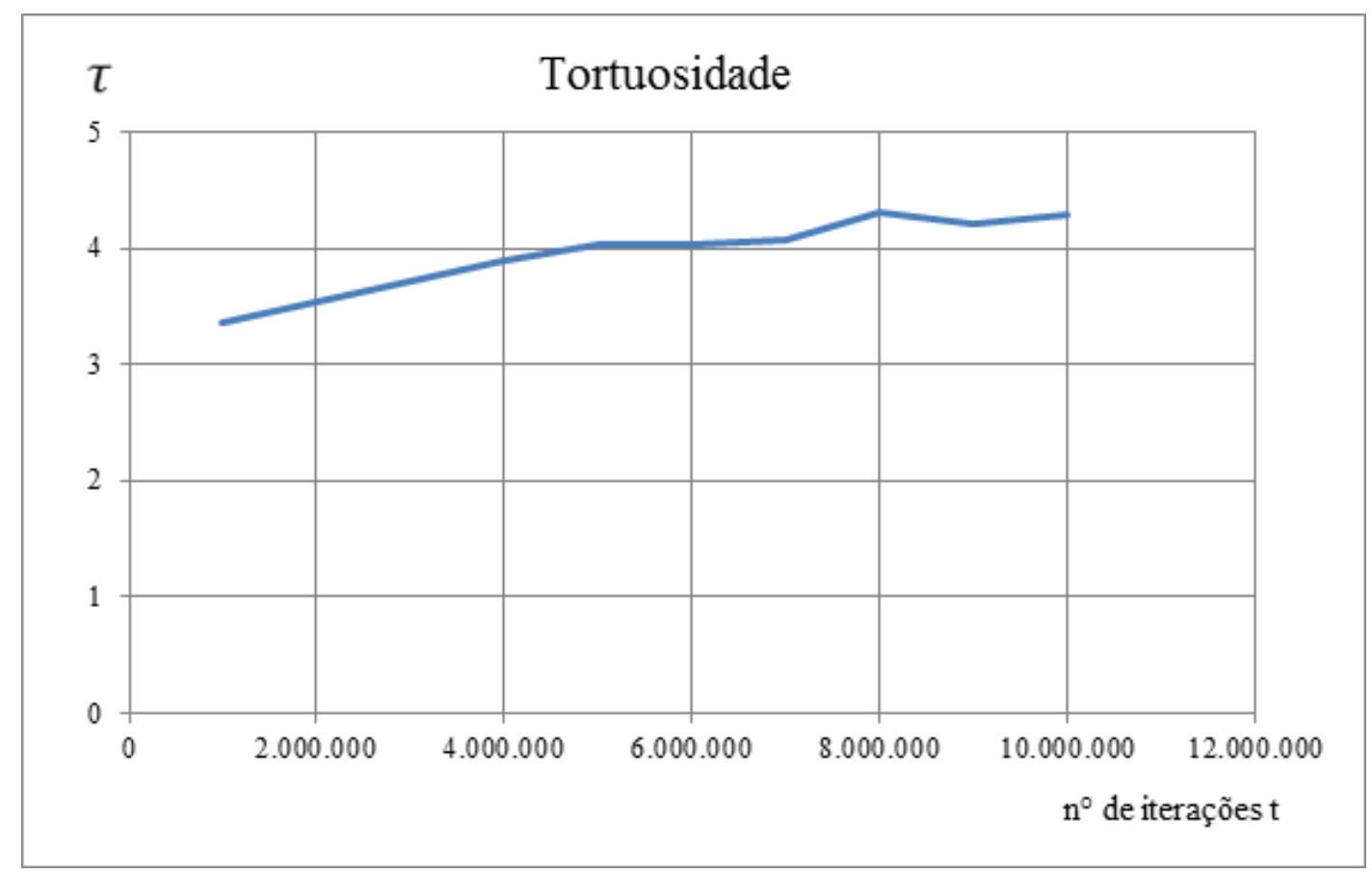

Figura 8: Gráfico da tortuosidade.

Os resultados médios da tortuosidade em cada direção, assim como a tortuosidade resultante e seus respectivos desvios padrão, são representados na Tabela 1. 
Tabela 1: Médias e desvios padrão da tortuosidade em 10.000.000 épocas para cada componente e sua resultante.

\begin{tabular}{l|l|l}
\hline TORTUOSIDADE & MÉDIA & DESVIO PADRÃO \\
\hline & 13,19 & 7,28 \\
\hline & 3,79 & 0,08 \\
\hline & 2,52 & 0,04 \\
\hline & 3,94 & 0,32 \\
\hline
\end{tabular}

\section{DISCUSSÃO}

Os resultados de porosidade total em torno de 32\% denotam uma tendência destes materiais cerâmicos utilizados como anodos em pilhas a combustível de óxido sólido. Estudos indicam que porosidades em torno destes valores proporcionam melhor permeabilidade dos gases reagentes [7].

A porosidade efetiva, que representa a relação entre o volume de poros que realmente se conectam formando canais e o volume total de poros, poderia ser considerada ocultando-se as formações porosas que não apresentam conectividade entre si. Desta forma, seriam contados somente os voxels pretos que possuíssem características morfológicas semelhantes a canais, porém não foi objeto de estudo deste trabalho.

A falta de convergência de $\tau_{x}$ é justificada pela existência de uma região livre de poros, destacada à direita na Figura 9. Esta região, aliada à consideração de ocorrência da simetria espacial, possivelmente funciona como uma barreira ao deslocamento dos andarilhos na direção “ $x$ ”, limitando o movimento a uma pequena região, o que aumenta a probabilidade de um movimento repetitivo, diminuindo a taxa de variação nessa região e consequentemente aumentando o valor da tortuosidade para essa componente.
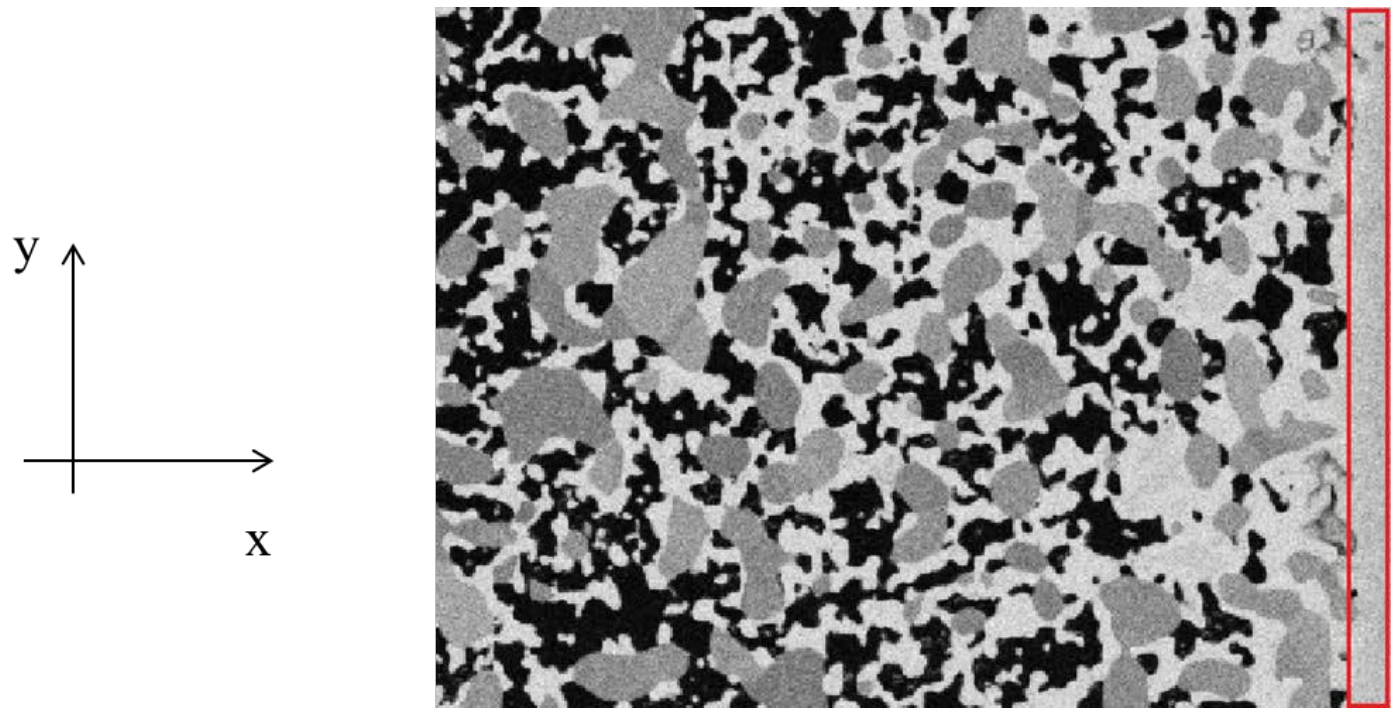

Figura 9: Demonstração da área interfacial sem conexão em “ $x$ ”.

A tortuosidade calculada em torno de 3,94 se mostra alinhada com os resultados obtidos por outros autores. SCHMIDT e TSAI [8] mostram valores que variam entre 5 e 7. WILSON et al.[9] demonstram um valor médio de 3,4 para a tortuosidade obtida através da quantificação tridimensional de um catodo Manganita de Lantânio dopada com Estrôncio e ZEI (LSM/ZEI), material de natureza morfológica semelhante àquele em questão.

\section{CONCLUSÕES}

O estudo realizado permite concluir que a técnica de reconstrução 3D produz resultados mais precisos que técnicas de classificação que utilizam projeções em duas dimensões. Quando analisa-se a superfície de um eletrodo através da geração de uma imagem bidimensional, observa-se uma estrutura resultante de projeções, ocultando os efeitos dos poros sinuosos nela existentes.

Para determinação de valores de tortuosidade buscou-se uma abordagem que simulasse um 
movimento difusional aleatório, que demonstrou ser uma aproximação coerente e aceitável fisicamente. Estudos que determinem sensibilidade às técnicas de geração de números pseudo-randômicos utilizadas e valores ótimos de convergência das funções poderiam otimizar os parâmetros de modelagem desse movimento difusional.

Com a evolução dos estudos em trabalhos futuros, pretende-se empregar técnicas de otimização de parâmetros, desse modo atingir-se-á uma eficiência cada vez maior dos algoritmos implementados, tornando possível o aumento no número de iterações e economia no tempo de máquina, além de maior aproveitamento das informações fornecidas pela reconstrução 3D.

\section{AGRADECIMENTOS}

Pesquisa desenvolvida junto ao Núcleo de Atendimento em Computação de Alto Desempenho (NACAD) da COPPE/UFRJ. Os autores gostariam de agradecer o apoio de colegas do Laboratório de Hidrogênio e de José Soares Coutinho Filho.

\section{BIBLIOGRAFIA}

[1] MIRANDA, P.E.V., DA CUNHA BUSTAMANTE, L.A., CERVEIRA, M., et al. "Análise Prospectiva da Introdução de Tecnologias Alternativas de Energia no Brasil”, julho 2003, Laboratório de Hidrogênio COPPE/UFRJ.

[2] AMADO, R.S., MALTA, L.F.B., GARRIDO. F.M.S., et al., "Pilhas a combustível de óxido sólido: materiais, componentes e configurações”, Química Nova, São Paulo, v. 30, n. 1, pp.189-197, fevereiro 2007.

[3] SINGHAL, S. C., KENDALL, K., "High Temperature Solid Oxide Fuel Cells: Fundamentals, Design and Applications”, New York - ELSEVIER, 2003.

[4] HOLZER, L., MÜNCH B., IWANSCHITZ B., et al., "Quantitative relationships between composition, particle size, triple phase boundary length and surface area in nickel-cermet anodes for Solid Oxide Fuel Cells”, Journal of Power Sources, v. 196, pp. 7076- 7089, 2011.

[5] IWAI, H., SHIKAZONO, N., MATSUI, T., et al., "Quantification of SOFC anode microstructure based on dual beam FIB-SEM technique”, Journal of Power Sources, v. 195, n. 4, pp. 955-961, 2010.

[6] KIM, A.S., CHEN, H., "Diffusive tortuosity factor of solid and soft cake layers: A random walk simulation approach”, Journal of Membrane Science, v. 279, n. 1-2, August 2006, pp. 129-139, 2006.

[7] SIMWONIS, D., THÜLEN, H., DIAS, F.J, et al., "Properties of Ni/YSZ porous cermets for SOFC anode substrates prepared by tape casting and coat-mix ${ }^{\circledR}$ process”, Journal of Materials Processing Technology, v. 92-93, pp. 107-111, 30 August 1999.

[8] SCHMIDT, V.H., TSAI, C., "Anode-pore tortuosity in solid oxide fuel cells found from gas and current flow rates”, Journal of Power Sources, v. 180, n. 1, 15, pp. 253-264, May 2008.

[9] WILSON J.R., DUONG, A.T., GAMEIRO, M., et al., "Quantitative three-dimensional microstructure of a solid oxide fuel cell cathode”, Electrochemistry Communications, v. 11, n. 5, pp. 1052-1056, May 2009. 